Int. J. Electrochem. Sci., 13 (2018) 9007 - 9016

International Journal of

ELECTROCHEMICAL

SCIENCE

www.electrochemsci.org

\title{
Ball-like Pt Nanoparticles on GO-modified Carbon Fiber Cloth with High Electrocatalytic Activity for Methanol Oxidation
}

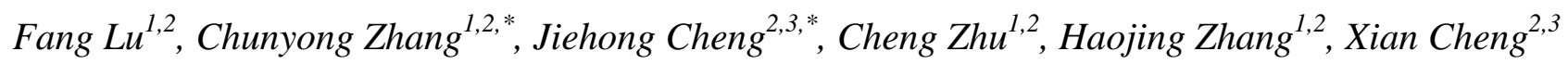 \\ ${ }^{1}$ Jiangsu Key Laboratory of Precious Metal C hemistry and Technology, Jiangsu University of \\ Technology, Changzhou, 213001, China \\ ${ }^{2}$ School of Chemistry and Environmental Engineering, Jiangsu University of Technology, Changzhou, \\ 213001, China \\ ${ }^{3}$ Jiangsu Province Key Laboratory of E-Waste Recycling, Jiangsu University of Technology, \\ Changzhou, 213001, China \\ Fang Lu, Chunyong Zhang, Jiehong Cheng contributed equally to this article. \\ "E-mail: zhangcy@jsut.edu.cn, cjh@jsut.edu.cn
}

doi; 10.20964/2018.09.67

Received: 24 May 2018 / Accepted: 30 June 2018 / Published: 5 August 2018

\begin{abstract}
A direct methanol fuel cell (DMFC) electrode based on the carbon fiber cloth (CFC) modified with wrap-like graphene oxide (GO) decorated with platinum nanoparticles was prepared by multicycle $\mathrm{CV}$ method. Also, the Pt/CFC composite and GO/CFC composite were prepared by multicycle $\mathrm{CV}$ and potentiostatic method, respectively. The four electrodes (GO-Pt/CFC, Pt/CFC, GO/CFC and CFC) were tested in a fuel cell for electro-oxidation of methanol and were analyzed by scanning electron microscopy (SEM) and X-Ray powder diffraction (XRD). The SEM image indicated that the surface of CFC was covered by a wrap-like graphene oxide (GO) film completely, which increased the contact area with methanol solution and provided more load points. And the Pt nanoparticles supported GO/CFC electrode possessed the ball-like morphology. The electrochemical measurements showed that the electrocatalytic peak current density of methanol oxidation of GO-Pt/CFC electrode (218 $\left.\mathrm{mA} / \mathrm{cm}^{2}\right)$ was about $27 \%$ higher than Pt/CFC electrode $\left(172 \mathrm{~mA} / \mathrm{cm}^{2}\right)$ and the steady-state current density of GO-Pt/CFC electrode was $57.6 \%, 114.5 \%$ and $497.9 \%$ higher than that of Pt/CFC, GO/CFC and $\mathrm{CFC}$ electrodes, respectively. And this date revealed that the ball-like morphology of $\mathrm{Pt}$ nanoparticles and a wrap-like GO film coated on CFC surface were favorable to improve the electrocatalytic oxidation activity of methanol.
\end{abstract}

Keywords: Direct Methanol Fuel Cell; Graphene Oxide; Pt nanoparticles; Electro-catalytic Activity; Carbon Fiber Cloth

$\underline{\text { FULL TEXT }}$ 
(C) 2018 The Authors. Published by ESG (www.electrochemsci.org). This article is an open access article distributed under the terms and conditions of the Creative Commons Attribution license (http://creativecommons.org/licenses/by/4.0/). 